\title{
Diplomacia y represión extraterritorial: la actuación del Servicio Exterior argentino en el 'caso Molfino'
}

\section{Diplomacy and extraterritorial repression: the involvement of the Argentine Foreign Service in the 'Molfino case'}

\author{
Facundo Fernández Barrio \\ Universidad de Buenos Aires \\ (Argentina) \\ facundofb@gmail.com
}

\begin{abstract}
Resumen
Este artículo analiza la actuación del Servicio Exterior argentino en el operativo de secuestro y desaparición de cuatro militantes argentinos en Perú, en junio de 1980. A partir de un acercamiento a un caso particular de represión extraterritorial, el presente trabajo se propone contribuir al conocimiento histórico sobre la coordinación represiva entre las dictaduras del Cono Sur e indagar sobre el papel que cumplieron en ella las instituciones regulares y formales del Estado Terrorista, en busca de complementar a las investigaciones historiográficas que se han centrado en el rol de las estructuras irregulares y clandestinas involucradas en dicha cooperación regional.
\end{abstract}

Palabras Clave: Diplomacia - Dictadura - Represión - Coordinación represiva 


\begin{abstract}
This article analyses the involvement of the Argentine Foreign Service in the kidnapping and forced disappearance operation of four Argentine activists in Peru, in June of 1980. Based on the approach to a specific case of extraterritorial repression, this analysis intends to contribute to the historical knowledge of repressive coordination between the dictatorships in the Southern Cone and to inquire into the role fulfilled therein by the formal and regular agencies of the Terrorist State, so as to supplement historiographical research which has focused on the role of irregular and clandestine structures involved in said regional cooperation.
\end{abstract}

Key Words: Diplomacy - Dictatorship - Repression - Repressive coordination

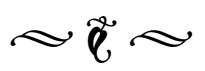

\section{Introducción}

La construcción y articulación de redes represivas entre las dictaduras de Seguridad Nacional del Cono Sur tomó forma como objeto de interés para la agenda historiográfica regional a mediados de la década pasada, cuando la politóloga estadounidense J. Patrice McSherry publicó el primer trabajo académico integral acerca de la coordinación de la represión en la región. ${ }^{1}$ Pese a que la investigación estuvo precedida y acompañada por trabajos periodísticos esclarecedores acerca de las operaciones represivas extraterritoriales en América Latina, con especial énfasis en la reconstrucción de la llamada Operación Cóndor, ${ }^{2}$ el libro de McSherry fue pionero en

1. MCSHERRY, J. Patrice, Los Estados Depredadores: la Operación Cóndor y la guerra encubierta en América Latina, LOM Ediciones / Banda Oriental, Santiago de Chile, 2005.

2. CALLONI, Stella, Los años del lobo. Operación Cóndor, Ediciones del Continente, Buenos Aires, 1999; BOCCIA PAZ, Alfredo, En los sótanos de los generales. Los documentos ocultos del Operativo Cóndor, Explolibro, la inauguración de una vigente línea académica de trabajo sostenida por investigadores latinoamericanos que buscan ampliar el panorama de la coordinación represiva a partir del relevamiento de archivos secretos descubiertos en los últimos años. ${ }^{3}$

Asunción, 2002; DINGES, John, Operación Cóndor. Una década de terrorismo internacional en el Cono Sur, Ediciones B, Santiago de Chile, 2004.

3. SERRA PADRÓS, Enrique, “Conexões externas da ditadura civil-militar uruguaia: a coordenação repressiva", en MEDEIROS DA ROCHA, Marcia (editora) IV Mostra de pesquisa do Arquivo Público do Estado do Rio Grande do Sul, Corag, Porto Alegre, 2006; CASSOL, Gissele, Prisão e tortura em terra estrangeira: a colaboração repressiva entre Brasil e Uruguay, Tesis de Maestría, Universidade Federal de Santa Maria, 2008; CUNHA, Luís, Operação Condor. O seqüestro dos uruguaios: uma reportagem dos tempos da ditadura, L\&PM, Porto Alegre, 2008; PENNA FILHO, Pio, "O Itamaraty nos anos de chumbo: O Centro de Informaçoes do Exterior (CIEX) e a repressão no Cone Sul (1966-1979)", en Revista Brasileira de Politica Internacional, Brasilia, 2009, N ${ }^{\circ}$ 2. Disponible en: <http://www.scielo.br/scielo.php?script=sci_ arttext\&pid=S0034-73292009000200003>; MARKANIAN, Vania, "Una mirada desde Uruguay 
McSherry definió a la coordinación represiva en el marco de la Operación Cóndor como un ejemplo histórico de lo que ella denominó como Estados paralelos: "El aparato del Estado paralelo era el lado invisible del Estado militar, pero estrechamente ligado a la cara visible, si bien de manera secreta. Escuadrones de la muerte paraestatales llevaron a cabo, de manera encubierta, las desapariciones, los actos de tortura, los asesinatos y las ejecuciones extrajudiciales, en su condición de apéndice del Estado visible". ${ }^{4}$ De esta forma, la autora estableció una asociación directa entre la articulación de las redes represivas regionales y la actividad clandestina de los Estados Terroristas latinoamericanos, vinculada con el accionar ilegal de las Fuerzas Armadas, los servicios de inteligencia y los escuadrones paraestatales asociados. McSherry caracterizó a la coordinación represiva como una construcción propia de las estructuras secretas e irregulares que ejecutaron materialmente las operaciones de inteligencia transfronterizas y el asesinato extraterritorial de exiliados. En cambio, la autora no se interesó por el papel desempeñado en la articulación represiva por las instituciones públicas formales que operaron en el marco de la legalidad de excepción típica del Estado Terrorista. ${ }^{5}$

a la coordinación represiva regional, 1973-1984", en BOHASLAVSKY, Ernesto (editor) Problemas de Historia Reciente en el Cono Sur, Prometeo, Buenos Aires, 2011; SLATMAN, Melisa, "Actividades extraterritoriales de la Armada Argentina durante la última dictadura civilmilitar de Seguridad Nacional (1976-1983)", en Aletheia, Buenos Aires, 2012, V III, N5. Disponible en: <http:// www.aletheia.fahce.unlp.edu.ar/numeros/numero-5/pdfs/ slatman.ok.pdf>.

4. MCSHERRY, J. Patrice, Los Estados Depredadores..., Op. Cit., p. 54.

5. Antes de que Eduardo Luis Duhalde acuñara la noción de "Estado Terrorista", Augusto Conte Mc Donell y Emilio Mignone habían descripto la organización de
Las investigaciones latinoamericanas acerca de la coordinación represiva que sucedieron al libro de McSherry se mantuvieron en la misma línea: se abocaron a describir y analizar las operaciones conjuntas encubiertas y a reconstruir las redes clandestinas de militares, espías y agentes paraestatales involucrados en ellas. Por el contrario, la actuación de las estructuras regulares del Estado en la articulación represiva regional, y en particular de la diplomacia civil y militar de las dictaduras conosureñas, no ha sido suficientemente investigada. Para el caso argentino, Melisa Slatman ha complejizado la perspectiva inaugural de McSherry, centrada casi exclusivamente en la Operación Cóndor, al señalar la existencia de una multiplicidad de modos de proyección extraterritorial del Estado Terrorista argentino, producto del alto nivel de autonomía alcanzado por cada una de las Fuerzas Armadas en la planificación y ejecución de la represión dentro del propio

la represión por parte del Estado argentino durante la última dictadura cívico-militar. En MIGNONE, Emilio y CONTE MAC DONELL, Augusto, La estrategia represiva de la dictadura militar. La doctrina del paralelismo global, Colihue, Buenos Aires, 1980. Los autores señalaron la existencia de dos niveles de normatividad estatal: uno de carácter público, centrado en la legalidad de excepción instaurada por el régimen dictatorial, y otro de carácter secreto, constituido por las acciones y pautas organizativas emanadas desde los servicios de inteligencia y los comandos mayores de las Fuerzas Armadas. Ppara un análisis sobre los planteos de Conte Mc Donell y Mignone, véase: D’ANTONIO, Débora y EIDELMAN, Ariel, "Antecedentes y genealogía de la historiografía sobre la Historia Reciente en la Argentina", en Nouveau Monde - Mondes Nouveaux, París, 2013. Disponible en: $<$ https://nuevomundo.revues.org/65882> Esta doble praxis del Estado Terrorista también fue advertida por Duhalde, quien dio cuenta de la imbricación entre una práctica estatal pública, desarrollada en un marco de pseudolegalidad, y un accionar militar clandestino que aplicó métodos criminales. El autor definió a dichas formas clandestinas de carácter permanente como una expresión paralela de la actividad estatal represiva. 
territorio nacional. ${ }^{6}$ No obstante, Slatman también se ha centrado fundamentalmente en las estructuras secretas nacidas en el seno de los servicios de inteligencia de las Fuerzas Armadas que actuaron fuera del espacio territorial nacional: el Grupo de Tareas Externo del Batallón de Inteligencia 601 del Ejército y el Grupo de Tareas 3.3/2 de la Armada. En cuanto al Servicio Exterior, la autora solo se ha interesado por identificar a algunos represores que salieron de la Argentina con credencial de agregados diplomáticos.

En la última década, han progresado nuevas líneas de investigación abocadas a la trama pseudolegal que configuró la violencia del Estado Terrorista argentino, cuyos intérpretes no fueron solo los grupos clandestinos y escuadrones secretos sino también los funcionarios de instituciones públicas de carácter formal. El Equipo de Antropología Jurídica y Política de la Facultad de Filosofía y Letras de la Universidad de Buenos Aires ha sido pionero en esta perspectiva. ${ }^{7}$ Bajo este enfoque, sus investigadores han abordado problemas tales como el funcionamiento de la morgue judicial durante la dictadura, ${ }^{8}$ la clasificación burocrática de personas

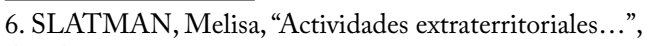
Op. Cit.

7. TISCORNIA, Sofía (compiladora) Burocracias y violencia. Ensayos sobre Antropología Jurídica, Antropofagia, Buenos Aires, 2004.

8. SARRABAYROUSE, María José, Poder Judicial y dictadura. El caso de la morgue judicial, IEI, Buenos Aires, 2003. desaparecidas ${ }^{9}$ o la apropiación de niños. ${ }^{10}$ Por su parte, Juan Pablo Bohoslavsky compiló una serie de trabajos acerca de la "complicidad" del cuerpo judicial argentino con el terrorismo de Estado. ${ }^{11}$ En sintonía con estas interpretaciones, Débora D'Antonio y Santiago Garaño han descripto la circulación de detenidos entre los centros clandestinos y las cárceles legales como parte de una misma estructura represiva. ${ }^{12} \mathrm{~A}$ su vez, Paula Canelo dio cuenta de la importante influencia de los consejeros civiles de las Juntas Militares en la configuración de los objetivos políticos del régimen dictatorial. ${ }^{13}$ Todos estos estudios señalaron la interconexión entre los circuitos criminales clandestinos apuntalados por el Estado Terrorista y las prácticas rutinarias de sus instituciones formales. Observaron los vínculos y vasos comunicantes entre las formas regulares del Estado y aquellas más irregulares. Estas investigaciones han contribuido a matizar las caracterizaciones del Estado

9. MORA, Nazarena, "El tratamiento burocrático y clasificación de personas desaparecidas (19761983)", en Avá, Posadas, 2008, №13. Disponible en: <http://www.scielo.org.ar/scielo.php?script=sci arttext\&pid=S1851-16942008000200007 > .

10. VILLALTA, Carla, “La apropiación de 'menores': entre hechos excepcionales y normalidades admitidas", en Estudios, Córdoba, 2005, №16. Disponible en: <https:// dialnet.unirioja.es/descarga/articulo/5364808.pdf>.

11. BOHOSLAVSKY, Juan Pablo (compilador) ${ }_{\dot{b}}$ Usted también, Doctor? Complicidad de jueces, fiscales y abogados durante la dictadura, Siglo XXI, Buenos Aires 2015.

12. GARAÑO, Santiago, Entre resistentes e 'irrecuperables': Memorias de ex presas y presos políticos (1974-1983), Tesis de Licenciatura, Universidad de Buenos Aires, 2008; D’ANTONIO, Débora, Transformaciones y experiencias carcelarias. Prisión política y sistema penitenciario en la Argentina entre 1974 y 1983. Tesis Doctoral, Universidad de Buenos Aires, 2010.

13. CANELO, Paula, La politica secreta de la última dictadura argentina, Edhasa, Buenos Aires, 2016. 
Terrorista como un bloque homogéneo, dando agencia histórica a actores públicos tan diversos como el Poder Judicial, la burocracia administrativa, el sistema penitenciario, los centros de menores, las oficinas políticas y otras instituciones estatales cuya dinámica cotidiana se superpuso con la de estructuras represivas de carácter secreto.

Pese a su potencia conceptual, esta matriz interpretativa no ha sido explotada por las líneas de investigación vigentes para analizar el problema de la coordinación represiva entre el Estado Terrorista argentino y las dictaduras del Cono Sur. En particular, el papel del servicio diplomático argentino en la articulación de las redes represivas regionales tampoco ha sido objeto de interés para la historiografía abocada a la política exterior de la dictadura, pese a que este subcampo de estudios ha tocado múltiples aspectos de la relación entre diplomacia y represión. ${ }^{14} \mathrm{Si}$ las investigaciones sobre la coordinación represiva no se han preocupado por el rol de los funcionarios diplomáticos

14. RUSSELL, Roberto, “Argentina y la política exterior del régimen autoritario (1976-1983): una evaluación preliminar", ponencia presentada en el Seminario América Latina y la crisis internacional, IRI-CIDE, Río de Janeiro, 1983; MONKMAN, Guillermo Alberto, The institutionalization of Doctrine of National Security in Argentina: the military foreign policy, University of South Carolina, Virginia, 1992; PAREDES, Alejandro, "La Operación Cóndor y la Guerra Fría", en Universum, Santiago de Chile, 2004, N 19, V. I, pp. 122-137. Disponible en: <http://universum.utalca.cl/contenido/ index-04-1/paredes.htm>; FRANCO, Marina, El exilio. Argentinos en Francia durante la dictadura, Siglo XXI, Buenos Aires, 2008; LLORET, Rodrigo, "Represión, derechos humanos y política exterior. El rol de los diplomáticos argentinos en el Comité de Derechos Humanos de la ONU (1976-1983)", en Papeles de Trabajo, Buenos Aires, 2016, N¹7, V.X, pp. 126-146. Disponible en: <http://www.unsam.edu. ar/revistasacademicas/index.php/papdetrab/article/ view/73/105>. (civiles y militares), los trabajos sobre la diplomacia del régimen militar tampoco han abordado a la coordinación represiva como un problema asociado. Consideramos apropiado concretar ese entrecruzamiento, a fin de revisar la tesis de McSherry acerca de una cooperación represiva regional cuyas protagonistas excluyentes habrían sido las estructuras secretas y clandestinas típicas de los "Estados depredadores". Creemos que es posible ampliar el panorama del conocimiento acerca de la coordinación de la represión entre las dictaduras del Cono Sur a partir de un análisis sobre el papel desempeñado en ella por las instituciones regulares del Estado Terrorista. El presente trabajo se propone realizar un aporte en esta dirección, consistente en estudiar la actuación de un relevante actor institucional formal, el Servicio Exterior argentino, en un caso particular de represión extraterritorial. Esta perspectiva no pretende impugnar sino complementar a los trabajos historiográficos que han centrado sus análisis en las redes clandestinas integradas por miembros de las Fuerzas Armadas, los servicios de inteligencia y los grupos paraestatales asociados en la cooperación represiva regional.

Es posible distinguir cuatro momentos diferenciados de la acción represiva extraterritorial del régimen militar argentino. En primer lugar, las desapariciones de ciudadanos argentinos en Uruguay, Paraguay y Brasil entre 1976 y 1978, asociadas a la llamada Operación Cóndor y relacionadas con la actividad extraterritorial de la Secretaría de Inteligencia del Estado. En segundo lugar, las acciones represivas en el exterior desarrolladas en ese mismo período por el Grupo de Tareas 3.3/2 de la Armada argentina en Uruguay, Paraguay y Perú. En tercer lugar, las operaciones extraterritoriales llevadas a cabo 
por el Batallón de Inteligencia 601 del Ejército argentino entre 1978 y 1980 en Brasil, Perú y México, dirigidas a contrarrestar la llamada Contraofensiva de Montoneros. A este tercer momento corresponde el caso Molfino, que estudiaremos en el presente trabajo. Por último, la transferencia de expertise en materia represiva por parte de las Fuerzas Armadas argentinas a la dictadura boliviana de Luis García Meza Tejada entre 1980 y 1981, que incluyó acuerdos de asesoría y entrenamiento de oficiales bolivianos por parte de represores argentinos enviados a Bolivia.

Nuestra hipótesis de trabajo es que el Servicio Exterior argentino habría sido un partícipe necesario en la ejecución efectiva y eficaz de la represión extraterritorial llevada adelante por el régimen militar. En las siguientes líneas intentaremos puntualizar esta hipótesis a partir de un análisis sobre la incidencia que tuvieron las embajadas argentinas en Lima, La Paz y Madrid en el operativo de secuestro y asesinato de Norma Esther Gianetti de Molfino y otros tres militantes argentinos a mediados de 1980.

\section{El caso Molfino}

En la mañana del lunes 9 de junio de 1980, un grupo de suboficiales del Servicio de Inteligencia del Ejército (SIE) de Perú fue citado de emergencia en el auditorio del Cuartel General del Ejército, conocido como el "Pentagonito" de Lima. ${ }^{15}$ Allí los esperaban

15. Para la reconstrucción fáctica del 'caso Molfino', en este apartado, hemos utilizado (salvo donde se aclara el uso de otras fuentes) el libro de UCEDA, Ricardo, Muerte en el Pentagonito. Los cementerios secretos del Ejército peruano, Planeta, Lima, 2004 (basada en el testimonio de un ex oficial peruano que participó en el operativo de secuestro y tortura).

136 el jefe del SIE, coronel Martínez Garay; el jefe del SIE2, comandante Oswaldo Hernández Hurtado y un grupo de desconocidos vestidos de civil. Uno de ellos se presentó como coronel del Ejército argentino. Explicó que los servicios de inteligencia de su país creían que miembros de Montoneros intentarían asesinar a Jorge Rafael Videla el próximo 28 de julio, cuando asistiera como invitado oficial al traspaso de mando del general Francisco Morales Bermúdez al presidente electo Fernando Belaúnde. El coronel agregó que los Montoneros ya estaban en Lima y pidió colaboración del SIE para capturarlos.

Además de solicitar el apoyo de sus pares peruanos, los represores argentinos llegados al Pentagonito -dos coroneles, un comandante, un capitán médico, un empleado civil del Ejército y seis suboficiales de inteligencia, cuyas identidadesnunca pudieron ser establecidas-les anunciaron a sus interlocutores que traían con ellos a un miembro de Montoneros que había sido detenido y que colaboraría para capturar a otros integrantes de la Organización. Bajo tortura, Federico Frías Alberga, un dirigente metalúrgico de La Plata con rango de oficial en el Movimiento Peronista Montonero, había informado sobre una cita clandestina a la que debía asistir en Lima. Algunas semanas antes, en Panamá, el jefe montonero Roberto Perdía le había ordenado a Frías que viajara a la capital peruana como parte de una avanzada de cuadros que habían llegado a Lima desde principios de aquel año. Unos doce militantes ya se encontraban en la ciudad, distribuidos en dos departamentos de alquiler, y esperaban el arribo de otros compañeros que completarían un grupo total de unas veinte personas.

Perdía ha negado tajantemente que la cumbre montonera en Perú tuviera algo que ver con 
un plan para asesinar a Videla. ${ }^{16}$ Sea como fuera, Frías había sido interceptado por sus perseguidores, quienes ahora se disponían a utilizarlo como señuelo para continuar con la cadena de secuestros en Lima. En la tarde del miércoles 11 de junio, uno de los suboficiales de inteligencia argentinos al que llamaban "Lito" alistó a Frías para que, de acuerdo con lo que había informado bajo tortura, acudiera a la cita con su contacto en el parque Kennedy de la capital peruana. Justo antes de partir hacia la cita, Frías intentó escapar corriendo. La persecución fue escandalosa. Lito hizo cinco disparos en plena calle y provocó la intervención de un patrullero policial. Logró atrapar a Frías y le dio un culatazo en la cabeza para callarlo. Lo sujetó a su propia muñeca con un par de esposas. El ciudadano peruano Pablo Clavijo, testigo casual del intento de escape y recaptura de Frías, declaró luego ante la Justicia que, después del patrullero, también apareció en escena "un auto que parecía de los que usan los diplomáticos, manejado también por un hombre con aspecto de diplomático". ${ }^{17}$ Frías, Lito y Clavijo fueron trasladados por el recién llegado a una guardia médica y después a una comisaría. Una vez allí, Lito pidió un teléfono y habló con el jefe del SIE peruano. Media hora después llegaron los coroneles Martínez Garay y Oswaldo Hernández, quienes lograron que los argentinos les fueran entregados. En su declaración testimonial, Clavijo no aclaró cuál era la nacionalidad del hombre con aspecto de diplomático. Sin embargo, una conversación que mantuvo con él nos permite inferir que era peruano. Tras dialogar con el comisario, el diplomático le dijo a Clavijo: "De todo lo que

16. Ídem, p. 362.

\section{Legajo de la Comisión Nacional sobre la}

Desaparición de Personas (CONADEP) de Joaquín Frías. has visto, mejor te callas: ni yo sé bien de qué se trata. Además, por dos o tres tipos no vamos a malograr las relaciones de Perú con Argentina. Mejor olvidate de todo". ${ }^{18}$

Esa noche, Frías fue otra vez torturado. Confesó que había dado una fecha falsa: la cita no era el miércoles 11 sino el jueves 12 . Los represores argentinos y peruanos volvieron a organizar el operativo para el día siguiente. El contacto que debía encontrarse con Frías era María Inés Raverta, una joven montonera de 24 años, madre de dos niñas y ex esposa de Mario Montoto, por entonces, secretario de Mario Firmenich. Raverta había aterrizado poco antes en Lima para coordinar las reuniones de Montoneros. Aquel jueves llegó al parque Kennedy acompañada por Gustavo Molfino, otro miembro de Montoneros, quien junto a su madre Norma Esther Giannetti de Molfino se había encargado de conseguir los departamentos seguros para las reuniones. Molfino se despidió de Raverta a algunos cientos de metros del punto donde ella se encontraría con Frías. Apenas hizo contacto con el señuelo, Raverta fue capturada por el grupo binacional de represores y trasladada al recreo militar de Playa Hondable, unos cincuenta kilómetros al norte de Lima. Allí fue entregada al jefe del SIE2, comandante Hernández, quien la dejó en manos de sus colegas argentinos. Unos ocho represores entre ellos, el oficial médico que había sido visto en el Pentagonito- la sometieron a una extensa sesión de picana eléctrica. Raverta resistió hasta que sus captores la pusieron frente a frente con Frías, quien ya había entregado información bajo tortura. Raverta comprendió que su silencio era inútil.

18. Ibídem. 
Para ese momento, el departamento de la calle Madrid en el que se escondían Perdía y los demás montoneros ya había sido evacuado y vaciado de armas. Ante la ausencia prolongada de Raverta, Perdía había decidido que todos los militantes abandonaran el lugar con excepción de Giannetti de Molfino y su hijo Gustavo, quien había salido por unas horas luego de la reunión. Para las seis y media de la tarde de ese mismo jueves, en el departamento solo quedaba una anciana en apariencia ajena a cualquier tipo de actividad política. Cuando regresó al departamento, Gustavo Molfino encontró la cuadra rodeada. Su madre le ordenó por teléfono que huyera. Al caer la noche, unos treinta hombres entraron al edificio y se llevaron a Norma Esther Giannetti de Molfino envuelta en una frazada, ante la mirada incrédula de los vecinos. La trasladaron a Playa Hondable, donde fue sometida al mismo suplicio que Raverta. Casi en simultáneo, un segundo grupo de represores argentinos y peruanos irrumpió en otro local de Montoneros en Lima y se llevó a la cuarta víctima: Julio César Ramírez, un ex preso político cordobés recién llegado a Perú.

El SIE peruano y los militares argentinos siguieron trabajando en cooperación hasta el domingo 15 de junio, cuando el SIE decidió poner fin a su participación en el operativo conjunto. Esa mañana, el periódico Diario de Marka había dado la primera información pública sobre el rapto de Frías, Raverta, Molfino y Ramírez. La operación ya no era secreta; el escándalo era inminente. Además, Perdía y los demás montoneros presentes en Lima ya se encontraban a salvo gracias al médico peruano Antonio Meza Cuadra, diputado electo y secretario general del Partido Socialista Revolucionario (PSR). Alertado por Gustavo Molfino sobre el secuestro de 138 su madre, Meza Cuadra había organizado el salvataje de los miembros de Montoneros que seguían en la ciudad. En la noche del jueves, los había reunido a todos en su casa y luego había dispuesto su traslado a locales seguros del PSR en distintos puntos de Lima. Desde ese momento, Meza Cuadra se había dedicado a denunciar los secuestros.

Pero ya era tarde para los cuatro raptados. La desaparición de Frías fue la primera en consumarse: jamás se supo si alguna vez salió vivo o muerto de Perú. Su hijo Joaquín Frías ha dicho que un militar retirado le aseguró que su padre murió fusilado en Campo de Mayo, pero esa versión no pudo ser confirmada por la familia. ${ }^{19}$

En cuanto a Raverta, Molfino y Ramírez, el SIE peruano los deportó a Bolivia. La dictadura de Morález Bermúdez lo anunció públicamente. Sin embargo, el gobierno democrático boliviano de Lidia Gueiler desmintió que su país hubiera recibido a los prisioneros argentinos. Hoy sabemos que el traslado sí pudo haber ocurrido. El general peruano Pedro Ritcher Prada, entonces comandante del Ejército y Ministro de Guerra, conserva como pruebas la copia de un acta de recepción de los tres detenidos firmada por el inspector de Migraciones de la localidad fronteriza boliviana de Desaguadero; y seis fotografías que corresponden a Raverta, Molfino y Ramírez en el instante previo a su presunto traspaso al país vecino. ${ }^{20}$ Ritcher Prada ha dicho también que el jefe de la Dirección de Inteligencia del Ejército (DINTE) de Perú,

19. Esa información fue sumada por Joaquín Frías al legajo CONADEP de su padre en 2013.

20. UCEDA, Ricardo, Muerte en el Pentagonito..., Op. Cit. 
general Germán Ruiz Figueroa, había previsto trasladar a los tres argentinos a Chile, pero que él ordenó cambiar su ruta hacia Bolivia ya que en el país de Augusto Pinochet les esperaba una muerte segura.

En rigor, Bolivia también era un destino funesto para los secuestrados. Es factible que la presidenta Gueiler ni siquiera estuviera enterada del ingreso de los argentinos a su país: las Fuerzas Armadas bolivianas y los grupos paramilitares asociados a ellas operaban con total autonomía del gobierno democrático y se preparaban para el golpe de Estado que daría el general García Meza apenas un mes después. El ex dictador peruano Morales Bermúdez ha declarado que era previsible que las fuerzas de seguridad bolivianas pusieran a los tres detenidos a disposición de sus pares argentinos, con quienes mantenían estrechas relaciones y quienes se movían a sus anchas en La Paz.

En diciembre de 1980, el abogado boliviano Aníbal Aguilar Peñarrieta, presidente de la sede en Bolivia de la Asociación Latinoamericana de Abogados de Derechos Humanos y dirigente del Movimiento Nacionalista Revolucionario (MNR), difundió una nueva información sobre el derrotero de los secuestrados. Según la fuente, estos habían sido entregados el 17 de junio a un tal capitán Roldán, pseudónimo de Fernando Riveros, un paramilitar bajo las órdenes del entonces coronel del Ejército boliviano Luis Arce Gómez, reconocido amigo de los represores argentinos y luego ministro del Interior de la dictadura de García Meza. Siempre de acuerdo con la versión reproducida por Aguilar Peñarrieta, Raverta, Molfino y Ramírez fueron llevados a La Paz, a la Sección II del Ejército, que dependía de Arce Gómez. Allí fueron interrogados y torturados por militares de nacionalidad argentina. Raverta y Ramírez habrían muerto por efecto de los tormentos sufridos. El coronel argentino Osvaldo Chimeno -quien se desempeñaba como asesor del Estado Mayor del Ejército de Bolivia en un curso de inteligencia estratégica dictado para militares bolivianos- y un tal Néstor Vignola han sido señalados como sus verdugos. ${ }^{21}$ De Raverta no se supo nunca más nada. De Ramírez y Molfino habría novedades unas semanas después, desde Madrid.

\section{La incidencia de las embajadas en Lima y La Paz}

E1 25 de marzo de 1980, casi tres meses antes de que los represores argentinos hicieran su presentación en el Pentagonito de Lima, el embajador argentino en esa ciudad, contralmirante Luis Sánchez Moreno, ya había advertido en un cable secreto a Buenos Aires: "Se tiene conocimiento por fuente oficial local que estarían ingresando delincuentes montoneros a Perú". ${ }^{22}$ La versión del representante diplomático acerca de que las autoridades de Perú habrían advertido a la embajada argentina sobre el arribo de miembros de montoneros al país andino contradice la del general peruano Ritcher Prada, quien ha dicho

21. Según versión de Ernesto Jauretche y Alicia Pierini en una investigación publicada en el diario Página/12, bajo el título "Guerra sucia en el Perú", en febrero de 1999. Disponible en: <http://www.pagina12.com. ar/1999/99-02/99-02-07/pag10.htm>.

22. Cable reservado $\mathrm{N}^{\circ} 326$ correspondiente a la desclasificación 408/2009 de la Comisión de Relevamiento para la Recuperación de la Memoria Histórica de la Cancillería argentina. A este acervo documental, conocido como "Colección Forti", corresponden todos los cables diplomáticos que citaremos de aquí en más. 
que fue el agregado militar argentino en Lima, coronel Manuel Saint Amant, quien informó al gobierno peruano sobre la presencia de militantes montoneros. En cualquier caso, queda probado que, desde los primeros meses de 1980, los funcionarios diplomáticos de la Cancillería argentina estaban al tanto de que la Contraofensiva de Montoneros había hecho pie en Perú. ${ }^{23}$ En sus comunicaciones con Buenos Aires, Sánchez Moreno exhibía un sensible manejo de información. E1 26 de marzo, envió otro despacho a la Argentina en el que alertó: "Indicios indicarían la posibilidad de existencia de elementos de escucha subrepticia en Cancillería que podrían no corresponder a servicios de inteligencia peruanos. A tenor de las normas de contrainteligencia, pido urgente inspección técnica". ${ }^{24} \mathrm{El}$ embajador argentino no era un inexperto en la "lucha contra la subversión”. En 1976, había estado al frente del Comando Naval del Área Fluvial y había tenido bajo su mando el centro clandestino de detención que funcionó en la Prefectura de Zárate. Lo mismo puede decirse del agregado Saint Amant, quien había sido jefe del Ârea Militar 132 en la provincia de Buenos Aires y quien décadas después sería condenado por

23. Para una aproximación a la experiencia histórica de la Contraofensiva Estratégica Montonera, véase CONFINO, Hernán Eduardo, "Tensiones de un retorno: La Contraofensiva Estratégica Montonera de 1979 y 1980 en Argentina”, en Izquierdas, Santiago de Chile, 2016, N 28, pp. 274-291. Disponible en: <http://www. scielo.cl/pdf/izquierdas/n28/art11.pdf $>$.

24. Cable Nº 333 (408/2009). Unos veinte días después, el 17 de abril, el Ministro de Relaciones Exteriores, brigadier Carlos Washington Pastor, firmó una resolución secreta en la que consideró "urgentemente necesario extremar las medidas de seguridad existentes en los inmuebles que ocupan las embajadas en Perú y Guatemala" y estimó procedente "asignarles las sumas necesarias para instrumentar las instalaciones de seguridad que sean menester” (Res. 0481-1980).

140
15 delitos de privación ilegítima de la libertad, amenazas, tormentos y homicidio en perjuicio de 76 víctimas en las localidades de San Nicolás, San Pedro y Pergamino.

Cuando Frías, Raverta, Molfino y Ramírez fueron secuestrados, tanto en la Argentina como en Perú circuló una extendida versión acerca de que había existido una coordinación de alto nivel entre Ritcher Prada y el entonces comandante general del Ejército argentino, Leopoldo Fortunato Galtieri, para trasladar y apresar a unos quince montoneros que habían arribado a Lima. Según publicó entonces la prensa peruana, el embajador Sánchez Moreno habría tenido participación personal en las gestiones de Galtieri ante Ritcher Prada. ${ }^{25}$ Éste último ha negado la existencia de tales gestiones, y en cambio ha dicho que el gobierno militar peruano intervino en el operativo contra Montoneros porque quería evitar actos desestabilizadores en pleno traspaso de mando. Según Ritcher Prada, "si hubo argentinos en locales militares peruanos, puede haber sido porque la agregaduría militar argentina hizo coordinaciones con el SIE, pero a ese nivel". ${ }^{26}$

La activa intervención de la embajada argentina en Perú, y en particular de Sánchez Moreno y Saint Amant, fue reflejada por la prensa peruana de la época. Según otro informe recogido en el legajo CONADEP de Ramírez, el jefe del DINTE de Perú, general Ruiz Figueroa, "fue usado para mantener comunicación permanente con los agentes

25. Según un artículo de la revista peruana Equis incluido en el legajo CONADEP de Norma Esther Giannetti de Molfino.

26. UCEDA, Ricardo, Muerte en el Pentagonito..., Op. Cit., p. 363. 
argentinos, a través del embajador argentino, contralmirante Luis Sánchez Moreno, y el agregado militar de la embajada". ${ }^{27}$

El 13 de junio de 1980, un día después del secuestro de Raverta y Molfino, Sánchez Moreno envió un cable secreto con carácter de "muy urgente" a Buenos Aires en el que anunciaba: "Viajaré [a la Argentina] en el vuelo AR385 del día 15. Agradeceré gestionar audiencia con S. E. Señor Ministro el día 16 o 17 y con Excmo. Señor Presidente entre el 17 y 19 inclusive". Dos días más tarde, pocas horas antes del secuestro de Julio César Ramírez, el Diario de Marka de Perú informó sobre el viaje que el embajador argentino realizaría esa misma tarde a su país "por motivos que no dio a conocer". Según la publicación, Sánchez Moreno y otros funcionarios de la embajada habían tenido una reunión de emergencia el día anterior. El agregado de prensa de la representación argentina, Mario Peschiutta, dijo ese día a los periodistas que no disponía de ninguna información oficial sobre la detención de los montoneros ya que no se había hecho ninguna denuncia en el consulado argentino, "que es la instancia que debe tramitar esos problemas". El funcionario agregó que Sánchez Moreno viajaba a su país "para atender asuntos oficiales". El Diario de Marka completaba la información de aquel 15 de junio con un sugestivo dato adicional: "De fuentes cercanas a la embajada argentina se supo que en la mañana de ayer hubo una entrevista entre el embajador Luis Sánchez Moreno y el general Pedro Ritcher Prada, que no pudo ser confirmada. Voceros del Ministerio

27. Según una solicitada de la Comisión Argentina de Derechos Humanos (CADHU), bajo el título "Represión que no conoce fronteras", citada en el legajo CONADEP de Julio César Ramírez. de Guerra y de la embajada argentina negaron toda relación mutua". ${ }^{28}$

Al día siguiente, el mismo periódico publicó un informe en el que dio cuenta de un tenso intercambio verbal entre Sánchez Moreno y algunos periodistas que lo habían abordado en la puerta de la embajada. El representante diplomático les dijo entonces que la denuncia del secuestro de los militantes argentinos era parte de una campaña internacional de desprestigio contra el gobierno de Videla en vísperas de la Asamblea General de la Organización de Estados Americanos (OEA), en la que se tratarían las violaciones a los Derechos Humanos en América Latina. Agregó que desconocía si se había producido o no el secuestro, afirmó que no disponía de más información que la publicada por la prensa, negó que su viaje a Buenos Aires tuviera algo que ver con el caso y se excusó de entrar en detalles para ser "respetuoso de la no injerencia en asuntos internos de países amigos". ${ }^{29}$

En las semanas siguientes, Sánchez Moreno se mantuvo muy activo en el seguimiento y monitoreo del caso Molfino y compañía. Entre el 17 de junio y el 3 de noviembre de 1980, el embajador argentino y un ministro consejero de apellido Ataide enviaron al menos 17 cables a Buenos Aires en los que remitieron resúmenes de lo publicado por medios gráficos y agencias de noticias sobre la desaparición de los cuatro argentinos; informes sobre acciones de denuncia y protesta realizadas por dirigentes $\mathrm{y}$ organizaciones de izquierda peruanas; y ocasionales pedidos de instrucciones acerca

28. Según un artículo del periódico peruano Diario de Marka incluido en el legajo CONADEP de Julio César Ramírez.

29. Cable $\mathrm{N}^{\circ} 713$ (408/2009). 
de cómo actuar frente al caso. En uno de esos despachos, Sánchez Moreno advirtió que la existencia de conflictos sindicales y huelgas en Perú facilitaba "la capacidad de movilización de elementos extremistas que, organizando manifestaciones para reclamos sindicales, las utilizan para atacar al gobierno peruano y al argentino". ${ }^{30}$ En otro cable secreto, el embajador argentino llegó a sugerir una idea para "contrarrestar el efecto negativo" producido por un programa televisivo peruano en el que se había transmitido una entrevista a Videla intercalada con declaraciones de Gustavo Molfino, en las que éste denunciaba el secuestro de su madre. Sánchez Moreno solicitaba permiso de la Cancillería para rebatir las acusaciones desde otro programa de $\mathrm{TV}$, conducido por un periodista afín. ${ }^{31}$

Tan diligente como Sánchez Moreno fue el embajador argentino en La Paz, brigadier José María Romero, quien entre el 20 de junio y el 4 de julio de 1980 envió cinco cables a Buenos Aires referidos a las repercusiones públicas y mediáticas del anuncio hecho por el gobierno peruano acerca de que los detenidos argentinos habían sido deportados a Bolivia. Al igual que Sánchez Moreno y Saint Amant, Romero era un experimentado represor. En junio de 1955, había sido uno de los aviadores sublevados que ametrallaron a civiles durante el intento golpista contra Juan Domingo Perón. En 1976, como jefe del Área Militar 160, había tenido a su cargo los centros clandestinos "Comisaría 3 de Morón", "Hospital Posadas" y "Mansión Seré”, que dependía directamente de él.

E1 7 de julio, Romero envió un nuevo despacho a Buenos Aires en el que advertía: "La supuesta

30. Cable $\mathrm{N}^{\circ} 894$ (408/2009).

31. Cable $\mathrm{N}^{\circ} 1066$ (408/2009).

142 desaparición de subversivos argentinos que el gobierno peruano sostiene haber entregado a autoridades bolivianas, circunstancias que éstas no reconocen, continúa teniendo actualidad... El episodio es motivo de comentario en círculos locales y no debe descartarse que su estado público de alguna manera se intensifique, por ejemplo, como consecuencia de una interpelación en el Congreso". A continuación, Romero solicitaba "conocer el punto de vista de esa superioridad acerca de la actitud que debe adoptar esta embajada en caso de tener que manifestarse sobre el particular, lo que hasta el momento no habría sucedido dado las cordiales relaciones con la Cancillería local". ${ }^{32}$ La respuesta del Departamento para América del Sur de la Cancillería argentina, firmada por el director general de Política Exterior, Enrique Ros, llegó a La Paz al día siguiente: "En las actuales circunstancias, V. E. mantendrá discreto silencio". ${ }^{33}$

\section{Secuestrada en Perú, asesinada en España}

E1 16 de julio de 1980, dos hombres de nacionalidad argentina alquilaron una suite en el hotel Miralto de Madrid. El 21 de julio, la policía española dio cuenta del hallazgo en ese apartamento del cadáver de una mujer de unos cincuenta años. Las diligencias judiciales posteriores comprobaron que se trataba de Norma Esther Giannetti de Molfino. El cuerpo mostraba signos de haber muerto tres días antes. No presentaba evidencias exteriores de violencia física. Es posible que Molfino hubiera muerto por envenenamiento, aunque las causas clínicas de su muerte nunca fueron

32. Cable $\mathrm{N}^{\circ} 711$ (408/2009).

33. Cable $\mathrm{N}^{\circ} 386$ (408/2009). 
esclarecidas. Había llegado a Madrid el 18 de julio, en un vuelo procedente de Río de Janeiro. Desde entonces, había permanecido en el Miralto bajo custodia de los dos sujetos argentinos, quienes al día siguiente se habían negado a abrirle la puerta al personal de limpieza. Cuando el cadáver de Molfino fue hallado, ambos desconocidos ya habían desaparecido.

Al avanzar con la investigación del caso, la policía judicial española se topó con un verdadero montaje en la escena del crimen. Junto al cuerpo de la víctima fueron encontrados un pasaporte a su nombre y otro falso con el que Molfino había ingresado a España. Había, además, dos pasaportes que habían utilizado sus verdugos y que estaban a nombre de dos ciudadanos argentinos: Julio César Ramírez y un tal Luis Esteban Almirón. Luego se comprobó que la foto de Almirón correspondía en realidad a Ramírez. Ambos documentos eran los mismos que portaba Julio César Ramírez antes de su secuestro y desaparición en Perú, a donde había llegado bajo la identidad falsa de Almirón. En Madrid, los asesinos de Molfino se ocuparon de desperdigar el nombre de Ramírez por todas partes: utilizaron su firma para alquilar un auto y la suite en el hotel Miralto. La mentira se completó con otro detalle siniestro: en la habitación donde fue hallada Molfino, se encontraron varias huellas digitales pertenecientes a Ramírez, quien probablemente había sido asesinado en $\mathrm{La} \mathrm{Paz}$ varios días antes. Roberto Perdía ha sugerido que los represores argentinos podrían haber fabricado un sello dactilar con el dedo del cadáver de Ramírez para contaminar la escena del crimen en Madrid. ${ }^{34}$

34. UCEDA, Ricardo, Muerte en el Pentagonito..., Op.
El montaje apuntaba a instalar una hipótesis falsa en la opinión pública: si el cadáver de Molfino había sido encontrado en España, y si había indicios de que se había alojado allí junto a otro de los montoneros desaparecidos, no había razones para sospechar de un delito cometido por el régimen militar argentino. Existen al menos dos teorías no necesariamente excluyentes sobre las razones que llevaron a los represores argentinos a concluir en Madrid el operativo que habían iniciado en Perú. Según la Comisión Argentina de Derechos Humanos (CADHU), el asesinato en España fue cometido en respuesta a una solicitud directa del general Ritcher Prada a Videla para que se desviara la atención periodística del Ejército peruano. ${ }^{35}$ Otra versión señala que, tras el triunfo en las elecciones bolivianas del 29 de junio de Hernán Siles Suazo (MNR), quien había hecho campaña con la promesa de revisar a fondo las violaciones a los Derechos Humanos, los secuestradores de Molfino decidieron sacarla de La Paz y embarcarla en un vuelo comercial, con escala en Brasil, hacia la capital española, donde la esperaban sus asesinos. $^{36}$

\section{La incidencia de la embajada en Madrid}

El engaño urdido en Madrid no hubiera sido posible sin la colaboración del embajador argentino en esa ciudad, el civil Jorge Washington Ferreira, quien tiempo después

Cit., p. 369.

35. Legajo CONADEP de Norma Esther Gianetti de Molfino.

36. Según versión de Ernesto Jauretche y Alicia Pierini. Disponible en: <http://www.pagina12.com.ar/1999/9902/99-02-07/pag10.htm >. 
llegaría a ser interventor de la dictadura en la provincia de Entre Ríos. ${ }^{37}$ Ferreira gestionó con inusual celeridad los trámites necesarios para que la mujer muerta fuera identificada rápidamente como Giannetti de Molfino. ${ }^{38}$ La embajada argentina proporcionó a la policía judicial española un prontuario de la víctima confeccionado por la Policía Federal Argentina; y dos formularios de visitas penitenciarias correspondientes a 1976 y 1977, en los que figuraban las huellas dactiloscópicas de Molfino. ${ }^{39}$ Ferreira solicitó a las autoridades policiales que le extendieran "la correspondiente comunicación en el caso de que las fichas dactiloscópicas adjuntadas coincidan con las del cadáver hallado".

El $1^{\circ}$ de agosto, la policía judicial le confirmó al funcionario argentino que el cuerpo era de Molfino, y le entregó todos los detalles del caso que poseía hasta ese momento. Aquel mismo día, Ferreira organizó un encuentro con la prensa y difundió un comunicado en el que afirmaba que la aparición del cadáver de Molfino "deja en la más palmaria evidencia la falsedad de la campaña de desprestigio urdida contra las autoridades peruanas y argentinas" y "advierte, una vez más, de la peligrosidad que exhibe la subversión internacional en su intento de socavar las bases de nuestra sociedad occidental". ${ }^{40}$ Dos días después, una

37. El juez español Baltasar Garzón llegó a procesar a Ferreira y a pedir su extradición por el 'caso Molfino'.

38. Legajo CONADEP de Norma Esther Gianetti de Molfino, donde se incluyen las actuaciones de la Justicia española luego del hallazgo de su cadáver.

39. La delegación argentina también aportó copias de las huellas dactilares de Julio César Ramírez, remitidas desde Buenos Aires por la Policía Federal.

40. Según un artículo del diario español El País incluido en el legajo CONADEP de Norma Esther Gianetti de Molfino.

144 solicitada de la CADHU bajo el título "E1 terrorismo de Estado no tiene fronteras" alertó sobre el hecho de que "pese a que la Dirección General de Seguridad de España no concluyó la investigación, el dictador Videla dio instrucciones especiales al embajador argentino para que haga público el hecho distorsionando su verdadero sentido criminal". ${ }^{41}$

\section{A modo de conclusión}

Tras lo dicho hasta aquí, podemos concluir que el Servicio Exterior argentino jugó un papel destacado en el operativo de represión extraterritorial analizado, en la medida en que los funcionarios diplomáticos de las embajadas argentinas en Lima, La Paz y Madrid contribuyeron a la ejecución y el encubrimiento de la desaparición y el asesinato de los argentinos secuestrados en varios aspectos. En primer lugar, el funcionamiento de las embajadas en Perú y Bolivia como canales de información privilegiados para el régimen militar argentino en el monitoreo de las repercusiones públicas del operativo. Los embajadores Sánchez Moreno y Romero mantuvieron un contacto permanente y prolongado con las oficinas de la Cancillería en Buenos Aires con el objeto de informar sobre las derivaciones locales del caso, así como de sus efectos a nivel mediático y político. En segundo lugar, la actuación de los funcionarios del servicio exterior como nexos en la coordinación represiva entre los agentes argentinos y sus pares peruanos. Nos referimos particularmente a Sánchez Moreno y al agregado Saint Amant, ambos sindicados como interlocutores por la parte argentina ante los jerarcas y agentes de inteligencia

41. Legajo CONADEP de Norma Esther Gianetti de Molfino. 
del Ejército de Perú que intervinieron en el operativo. En tercer lugar, la capacidad de esos mismos funcionarios para recabar información sensible para la dictadura argentina. No es un detalle menor que, ya a principios de 1980, la embajada en Lima hubiera dado una temprana señal de alerta sobre los indicios de que Montoneros había comenzado su despliegue en Perú. Como tampoco lo es el hecho de que, en pleno operativo de secuestro de Molfino y compañía, Sánchez Moreno hubiera viajado de urgencia a Buenos Aires para reunirse en persona con Jorge Rafael Videla. En cuarto lugar, la activa participación de los embajadores mencionados en la campaña emprendida por el gobierno argentino para desligarse de los secuestros. Esto vale tanto para Sánchez Moreno como para Ferreira, quienes se esmeraron en presentar los sucesos como parte de una supuesta operación de "difamación" contra la dictadura de Videla. En quinto lugar, la relevante intervención de la embajada argentina en Madrid en las gestiones destinadas a desviar la investigación de la policía judicial española sobre el asesinato de Noemí Esther Giannetti de Molfino. Por último, no debe perderse de vista el hecho de que los miembros del servicio diplomático cuyo accionar hemos descripto fueran funcionarios comprometidos desde hacía años en la "lucha contra la subversión", lo que sugiere hasta qué punto las redes clandestinas de represión aparecían superpuestas e imbricadas con las estructuras pseudolegales del Estado Terrorista.

Esperamos que este análisis sobre la actuación del Servicio Exterior argentino en el caso Molfino sirva como acotada contribución a un nuevo modo de aproximación histórica frente al problema de la coordinación represiva en el Cono Sur. El hecho de que un relevante actor formal del Estado Terrorista haya tenido incidencia directa en este caso particular de represión extraterritorial invita a repensar la tesis clásica de McSherry acerca de una cooperación represiva internacional cuyos artífices exclusivos habrían sido los agentes secretos y clandestinos típicos de los "Estados depredadores", tradicionalmente asociados a sus Fuerzas Armadas, servicios de inteligencia y grupos paraestatales asociados. Sin negar el protagonismo de dichas estructuras irregulares, creemos que es preciso ampliar el foco de atención.
Recibido: 06-11-2016
Aceptado: 24-02-2017
Publicado: 06-06-2017 


\section{Bibliografía}

BOCCIA PAZ, Alfredo, En los sótanos de los generales. Los documentos ocultos del Operativo Cóndor, Explolibro, Asunción, 2002.

BOHOSLAVSKY, Juan Pablo (compilador) ¿Usted también, Doctor? Complicidad de jueces, fiscales y abogados durante la dictadura, Siglo XXI, Buenos Aires 2015.

CALLONI, Stella, Los años del lobo. Operación Cóndor, Ediciones del Continente, Buenos Aires, 1999.

CANELO, Paula, La politica secreta de la última dictadura argentina, Edhasa, Buenos Aires, 2016.

CASSOL, Gissele, Prisão e tortura em terra estrangeira: a colaboração repressiva entre Brasil e Uruguay, Tesis de Maestría, Universidade Federal de Santa Maria, 2008.

CONFINO, Hernán Eduardo, “Tensiones de un retorno: La Contraofensiva Estratégica Montonera de 1979 y 1980 en Argentina”, en Izquierdas, Santiago de Chile, 2016, N²8. Disponible en: <http://www. scielo.cl/pdf/izquierdas/n28/art11.pdf>.

CUNHA, Luís, Operação Condor. O seqüestro dos uruguaios: uma reportagem dos tempos da ditadura, L\&PM, Porto Alegre, 2008.

D'ANTONIO, Débora, Transformaciones y experiencias carcelarias. Prisión politica y sistema penitenciario en la Argentina entre 1974 y 1983. Tesis Doctoral, Universidad de Buenos Aires, 2010.

D'ANTONIO, Débora y EIDELMAN, Ariel, “Antecedentes y genealogía de la historiografía sobre la Historia Reciente en la Argentina”, en Nouveau Monde - Mondes Nouveaux, París, 2013. Disponible en: $<$ https://nuevomundo.revues.org/65882>.

DINGES, John, Operación Cóndor. Una década de terrorismo internacional en el Cono Sur, Ediciones B, Santiago de Chile, 2004.

FRANCO, Marina, El exilio. Argentinos en Francia durante la dictadura, Siglo XXI, Buenos Aires, 2008.

GARAÑO, Santiago, Entre resistentes e 'irrecuperables': Memorias de ex presas y presos politicos (1974-1983), Tesis de Licenciatura, Universidad de Buenos Aires, 2008.

LLORET, Rodrigo, "Represión, derechos humanos y política exterior. E1 rol de los diplomáticos argentinos en el Comité de Derechos Humanos de la ONU (1976-1983)”, en Papeles de Trabajo, Buenos Aires, 2016, $\mathrm{N}^{\circ}$ 16. Disponible en: <http://www.unsam.edu.ar/revistasacademicas/index.php/papdetrab/ 
article/view/73/105>.

MARKANIAN, Vania, “Una mirada desde Uruguay a la coordinación represiva regional, 1973-1984”, en BOHASLAVSKY, Ernesto (editor) Problemas de Historia Reciente en el Cono Sur, Prometeo, Buenos Aires, 2011.

MCSHERRY, J. Patrice, Los Estados Depredadores: la Operación Cóndor y la guerra encubierta en América Latina, LOM Ediciones / Banda Oriental, Santiago de Chile, 2005.

MIGNONE, Emilio y CONTE MAC DONELL, Augusto, La estrategia represiva de la dictadura militar. La doctrina del paralelismo global, Colihue, Buenos Aires, 1980.

MONKMAN, Guillermo Alberto, The institutionalization of Doctrine of National Security in Argentina: the military foreign policy, University of South Carolina, Virginia, 1992.

MORA, Nazarena, "El tratamiento burocrático y clasificación de personas desaparecidas (1976-1983)", en Avá, Posadas, 2008, N ${ }^{\circ}$ 13. Disponible en: <http://www.scielo.org.ar/scielo.php?script=sci_ arttext\&pid=S1851-16942008000200007>.

PAOLETTI, Alpio, Como a los nazis, como en Vietnam. Los campos de concentración en la Argentina, Contrapunto, Buenos Aires, 1987.

PAREDES, Alejandro, “La Operación Cóndor y la Guerra Fría”, en Universum, Santiago de Chile, 2004, N 19. Disponible en: <http://universum.utalca.cl/contenido/index-04-1/paredes.htm>.

PENNA FILHO, Pio, “O Itamaraty nos anos de chumbo: O Centro de Informaçoes do Exterior (CIEX) e a repressão no Cone Sul (1966-1979)”, en Revista Brasileira de Política Internacional, Brasilia, $2009, N^{\circ} 2$. Disponible en: <http://www.scielo.br/scielo.php?script=sci_arttext\&pid=S0034-73292009000200003>.

RUSSELL, Roberto, “Argentina y la política exterior del régimen autoritario (1976-1983): una evaluación preliminar", ponencia presentada en el Seminario América Latina y la crisis internacional, IRI-CIDE, Río de Janeiro, 1983.

SARRABAYROUSE, María José, Poder Judicial y dictadura. El caso de la morgue judicial, IEI, Buenos Aires, 2003.

SERRA PADRÓS, Enrique, “Conexões externas da ditadura civil-militar uruguaia: a coordenação repressiva”, en MEDEIROS DA ROCHA, Marcia (editora) IV Mostra de pesquisa do Arquivo Público do Estado do Rio Grande do Sul, Corag, Porto Alegre, 2006. 
SLATMAN, Melisa, "Actividades extraterritoriales de la Armada Argentina durante la última dictadura civil-militar de Seguridad Nacional (1976-1983)”, en Aletheia, Buenos Aires, 2012, V. III, N 5. Disponible en: <http://www.aletheia.fahce.unlp.edu.ar/numeros/numero-5/pdfs/slatman.ok.pdf>.

SLATMAN, Melisa, "Contrarrevolución en el Cono Sur de América Latina. El ciclo de dictaduras de Seguridad Nacional (1964-1990), en GUEVARA, Gustavo (coordinador) Sobre las revoluciones latinoamericanas, Newen Mapu, Buenos Aires, 2013.

TISCORNIA, Sofía (compiladora) Burocracias y violencia. Ensayos sobre Antropología Jurídica, Antropofagia, Buenos Aires, 2004.

UCEDA, Ricardo, Muerte en el Pentagonito. Los cementerios secretos del Ejército peruano, Planeta, Lima, 2004.

VILLALTA, Carla, “La apropiación de 'menores': entre hechos excepcionales y normalidades admitidas", en Estudios, Córdoba, 2005, N 16. Disponible en: <https://dialnet.unirioja.es/descarga/articulo/5364808. pdf>. 